ORIGINAL ARTICLE

\title{
Resource utilisation, length of hospital stay, and pattern of investigation during acute medical hospital admission
}

\author{
R McMullan, B Silke, K Bennett, S Callachand
}

Postgrad Med J 2004;80:23-26. doi: 10.1136/pgmi.2003.007500

\begin{abstract}
See end of article for authors' affiliations

Correspondence to: Dr B Silke, Department of Pharmacology and Therapeutics, Trinity Centre for Health Sciences, St James' Hospital, James' Street, Dublin 8, Ireland; silkeb@tcd.ie
\end{abstract}

Submitted 10 March 2003 Accepted 29 May 2003
Objectives: To describe the patient demographic characteristics and organisational factors that influence length of stay (LOS) among emergency medical admissions. Also, to describe differences in investigation practice among consultant physicians and to examine the impact of these on LOS.

Design: Prospective observational study.

Setting: General medicine department of a teaching hospital in Belfast, UK.

Participants: Data were recorded for patients who were admitted as emergencies and reviewed on the post-take ward rounds (PTWR) attended by the investigation coordinator.

Outcome measures: Non-laboratory investigations requested, LOS, and diagnosis on discharge.

Results: Of 830 episodes evaluated, the median LOS was 7 days (interquartile range 3-12 days); this was significantly longer for admissions on Fridays $(p=0.0011)$ and for patients managed on medical wards $(p<0.0001)$. There was a positive correlation between patient age and LOS $(r=0.32, p<0.0001)$. Chest radiographs $(p=0.002)$ and echocardiography $(p=0.015)$ were associated with a prolonged LOS; no investigations were associated with a shortened LOS. Diagnoses of congestive heart failure, respiratory disease, and cancer were associated with a longer LOS; a diagnosis of angina was associated with a shorter LOS. Considerable variation in investigation ordering, but no difference in LOS, was observed between consultants. High use of a given medical test did not correlate with high use of other tests.

Conclusion: A systematic means of dealing with the NHS resource crisis should include an improved organisational strategy as well as social care provision. A more unified approach to investigation practice should also have a sparing effect on resources.
W hile several investigators have previously reported factors responsible for the increasing use of medical investigations in various settings, ${ }^{1-7}$ as well as factors contributing to prolonged hospital inpatient episodes, there are few data describing the demographic characteristics, patterns of investigation, and length of stay (LOS) of patients admitted as emergencies to general medicine units in the UK. The principal objective of this study is to report these characteristics in a general medical department of a teaching hospital in Belfast, Northern Ireland. Furthermore, we aim to describe variations in the ordering of medical tests between general physicians and to identify correlations between the ordering of specific investigations and LOS. Moreover, we wished to determine, first, whether high use of a specific diagnostic procedure correlated with high use of other diagnostic procedures and, second, whether high use of such investigations influenced LOS.

\section{PATIENTS AND METHODS}

Data relating to emergency medical patients admitted to Belfast City Hospital between 1 June 2000 and 31 December 2000 were recorded. Belfast City Hospital, although a tertiary referral centre for various specialties, operates an alternate day acute general medical take-in serving as a secondary care centre for emergency medical admissions for the greater Belfast area. Patients were admitted directly to a variety of wards, many of which are not affiliated with a medical specialty, under the care of a named consultant physician. The investigations coordinator logged information during the post-take ward rounds (PTWR) he attended during this period. Data collected were basic demographic information, consultant responsible for care, Townsend deprivation index (based on postcode), LOS, and non-laboratory investigations requested during the consultant-led ward round on the first day after admission.

\section{Statistical methods}

Descriptive analyses are presented in the form of means, 95\% confidence intervals, medians, interquartile ranges (IQRs), and proportions. Associations between continuous measures were examined using Spearman's correlation, and associations between continuous and categorical measures were examined using non-parametric Wilcoxon rank sum tests, as the LOS was not normally distributed. Categorical measures were cross tabulated, and where appropriate $\chi^{2}$ tests were performed. For the purpose of examining associations multivariately, logistic regression was used, dichotomising LOS as up to eight days or eight days or more. Odds ratios and $95 \%$ confidence intervals are presented. Statistical significance at $\mathrm{p}<0.05$ is assumed throughout, and a Bonferroni correction is made for repeated statistical testing. All analyses were performed using the JMPin statistical package (version 3.2, SAS Institute Inc).

\section{RESULTS}

We evaluated 830 episodes among patients with a mean age of 64.5 (SD 18.0) years; 362 patients $(43.6 \%$ ) were female. Overall, 616 patients $(74.2 \%)$ were managed on a general medicine ward; the remaining 214 patients $(25.8 \%)$ were managed as "outliers" on wards affiliated with non-medical specialties. Fourteen different consultant physicians were

Abbreviations: DVT, deep vein thrombosis; ECG, electrocardiography; $I Q R$, interquartile range; LOS, length of stay; PTWR, post-take ward round 
responsible for the management of these patients, of which eight were full time NHS consultants and six held half time (joint NHS/university) academic appointments. All except one had a subspecialty interest as well as a commitment to acute general medical admissions. These interests included respiratory medicine $(n=5)$, metabolic medicine $(n=2)$, clinical pharmacology $(n=4)$, and gastroenterology $(n=2)$.

The median LOS was 7 days (IQR 3-12 days). This was significantly longer when the day of admission was Friday (median LOS 9 days; IQR 4-14 days). There was a positive correlation between patient age and LOS $(r=0.32$, $\mathrm{p}<0.0001)$. Moreover, medical wards had significantly longer LOS ( 7 days $v 5$ days, $\mathrm{p}<0.01$ ). LOS was not influenced by Townsend deprivation index, or admitting consultant (table 1).

Of all the investigations requested on the day after admission, only chest radiographs $(p=0.002)$ and echocardiography $(p=0.015)$ were associated with a prolonged LOS; no test request was associated with a shortened LOS. Requests for ECG, computed tomography imaging, deep vein thrombosis (DVT) related investigations, and gastrointestinal investigations were not associated with LOS (see table 1).

\begin{tabular}{|c|c|c|c|c|}
\hline Characteristic & $\begin{array}{l}\text { Median } \\
\text { (days) }\end{array}$ & IQR (days) & $\begin{array}{l}\text { No of } \\
\text { patients }\end{array}$ & p Value* \\
\hline \multicolumn{5}{|l|}{ Sex } \\
\hline Male & 6 & $3-11$ & 468 & \\
\hline Female & 7 & $3-12.75$ & 362 & 0.025 \\
\hline \multicolumn{5}{|l|}{ Day of week } \\
\hline Friday & 9 & $4-14$ & 91 & \\
\hline Another day & 6 & $3-11$ & 739 & $0.0011^{*}$ \\
\hline \multicolumn{5}{|l|}{ Ward } \\
\hline Medical & 7 & $3-13$ & 616 & \\
\hline Other & 5 & $2-11$ & 214 & $<0.0001^{*}$ \\
\hline \multicolumn{5}{|l|}{ Echo request } \\
\hline No & 6 & $3-12$ & 753 & \\
\hline Yes & 8 & $4-16$ & 77 & 0.015 \\
\hline \multicolumn{5}{|c|}{$\begin{array}{l}\text { Computed tomography } \\
\text { request }\end{array}$} \\
\hline No & 7 & $3-12$ & 655 & \\
\hline Yes & 6 & $3-11$ & 175 & 0.43 \\
\hline \multicolumn{5}{|l|}{ Electrocardiography } \\
\hline No & 7 & $3-12.5$ & 561 & \\
\hline Yes & 6 & $3-11$ & 269 & 0.34 \\
\hline \multicolumn{5}{|l|}{ Chest radiograph } \\
\hline No & 6 & $3-11.5$ & 621 & \\
\hline Yes & 8 & $4-14$ & 209 & $0.002^{*}$ \\
\hline \multicolumn{5}{|l|}{$\begin{array}{l}\text { Deep vein thrombosis } \\
\text { request }\end{array}$} \\
\hline No & 7 & $3-12$ & 777 & \\
\hline Yes & 6 & $3-11$ & 53 & 0.84 \\
\hline \multicolumn{5}{|c|}{ Gastrointestinal request } \\
\hline No & 6 & $3-12$ & 769 & \\
\hline Yes & 8 & $3-13.5$ & 61 & 0.53 \\
\hline \multicolumn{5}{|l|}{ Diagnosis } \\
\hline Respiratory & 9 & $5-13$ & 111 & \\
\hline Other & 6 & $3-12$ & 719 & $<0.0001^{*}$ \\
\hline Cardiac & 3 & $2-7$ & 107 & \\
\hline Other & 7 & $3-13$ & 723 & $<0.0001^{*}$ \\
\hline $\begin{array}{l}\text { Congestive heart } \\
\text { failure }\end{array}$ & 9.5 & $6.75-13.25$ & 54 & \\
\hline Other & 6 & $3-12$ & 776 & 0.005 \\
\hline $\begin{array}{l}\text { Angina/myocardial } \\
\text { infarction }\end{array}$ & 4 & $2-9.5$ & 52 & \\
\hline Other & 7 & $3-12$ & 778 & 0.038 \\
\hline Tumour & 13.5 & $7-19.25$ & 34 & \\
\hline Other & 6 & $3-12$ & 796 & $0.0001^{*}$ \\
\hline Stroke & 9 & $4-17.75$ & 50 & \\
\hline Other & 6 & $3-12$ & 780 & 0.018 \\
\hline Any infection & 4.5 & $3-9.25$ & 42 & \\
\hline Other & 7 & $3-12$ & 788 & 0.055 \\
\hline
\end{tabular}

*Applying a Bonferroni correction; only those $p$ values less than 0.003 are considered significant.

†Using non-parametric Wilcoxon rank sum test.
The diagnostic codes of the primary disease classification (ICD-10) at the time of discharge or death were evaluated; prolonged LOS was associated with the following primary diagnostic codings: respiratory ( 9 days $v 6$ days, $\mathrm{p}<0.001$ ), congestive heart failure (9.5 days $v 6$ days, $\mathrm{p}=0.005)$, tumour ( 13.5 days $v 6$ days, $\mathrm{p}=0.0001$ ), and stroke ( 9 days $v 6$ days, $\mathrm{p}=0.018$ ). Shorter LOS was associated with cardiac ( 3 days $v 7$ days, $\mathrm{p}<0.001$ ) and angina/myocardial infarction (4 days $v 7$ days, $\mathrm{p}=0.038$ ) diagnoses. There was a trend towards shortened LOS for infection related illnesses (4.5 days $v 7$ days, $\mathrm{p}=0.055$ ).

There was significant variation in test ordering between consultants in respect of certain investigations (table 2): these were abdominal ultrasonography, computed tomography of the brain, chest, abdomen, or pelvis and barium enema. The difference in request levels, for similar numbers of patients admitted, was striking: for common requests the variability ranged from 2.2 -fold to 3.4 -fold, and for gastrointestinal investigations a 15 -fold variation between the highest and lowest requesting consultants was observed. High computed tomography users $(\mathrm{n}=4$ consultants with a greater than $25 \%$ request rate) were no more likely to request a chest radiograph, ECG, or echocardiography than the other consultant medical staff; however, they had a consistently lower rate of request for gastrointestinal special investigations $\left(\chi^{2}=6.82, \mathrm{p}=0.0002\right)$ and DVT related investigations $\left(\chi^{2}=6.99, \mathrm{p}=0.0002\right)$.

The main factors of interest $(\mathrm{p}<0.10$ in univariate analyses) were studied simultaneously using multivariate logistic regression analysis. Table 3 presents adjusted odds ratios (with 95\% confidence intervals). This analysis shows that older age, outlying ward, and respiratory and tumour diagnostic codings were more predictive of LOSs of more than eight days, while a cardiac diagnostic coding was less predictive.

\section{DISCUSSION}

The median LOS for acute general medicine admissions in our study was seven days; those patients who were admitted on a Friday, were managed on medical wards, or were elderly remained in hospital for longer. Of all investigations ordered on the PTWR, only chest radiographs and echocardiograms were associated with a longer LOS. Although there was considerable variation in investigation ordering between consultant physicians, no significant difference in LOS was observed. Of interest, a high use of any given medical test did not correlate with a high use of other tests.

Factors that predict prolongation of the inpatient stay have been described in various patient populations in the USA and mainland Europe..$^{8-14}$ Furthermore, patterns in the ordering of medical tests and factors that determine the use of investigations have also been described in countries outside

Table 2 Resource utilisation (\% use) by consultant

\begin{tabular}{|c|c|c|c|}
\hline Investigation & $\begin{array}{l}\text { Minimum } \\
\text { (\% use) }\end{array}$ & $\begin{array}{l}\text { Maximum } \\
\text { (\% use) }\end{array}$ & $\begin{array}{l}\text { Variability } \\
\text { (maximum/ } \\
\text { minimum) }\end{array}$ \\
\hline Echo & 4.50 & 17.0 & 3.8 \\
\hline Computed tomography & 12.7 & 34.4 & 2.7 \\
\hline Electrocardiography & 13.3 & 45.4 & 3.4 \\
\hline Chest radiograph & 17.0 & 36.7 & 2.2 \\
\hline $\begin{array}{l}\text { Deep vein thrombosis } \\
\text { investigations } \dagger\end{array}$ & 3.23 & 10.64 & 3.3 \\
\hline $\begin{array}{l}\text { Gastrointestinal } \\
\text { investigations } \ddagger\end{array}$ & 1.72 & 25.81 & 15 \\
\hline
\end{tabular}

†Duplex Doppler, ventilation/perfusion scan, or venography. †Endoscopy or gastrointestinal radiology. 
Table 3 Adjusted odds ratios (with 95\% confidence intervals) from logistic regression analyses predicting LOS of eight days or more

\begin{tabular}{|c|c|c|c|}
\hline Variable & $\begin{array}{l}\text { Odds } \\
\text { ratio }\end{array}$ & $\begin{array}{l}95 \% \text { confidence } \\
\text { interval }\end{array}$ & p Value \\
\hline Sex (male $v$ female) & 0.79 & 0.58 to 1.07 & 0.13 \\
\hline $\begin{array}{l}\text { Age ( } 75 \text { years and over } v \text { less than } \\
65 \text { years) }\end{array}$ & 3.64 & 2.38 to 5.61 & $<0.0001$ \\
\hline $\begin{array}{l}\text { Age }(75 \text { years and over v } 65-74 \\
\text { years) }\end{array}$ & 1.15 & 0.73 to 1.83 & 0.55 \\
\hline Friday $v$ other days & 1.34 & 0.84 to 2.16 & 0.22 \\
\hline Ward (general medical $v$ outlying) & 1.77 & 1.25 to 2.52 & 0.0013 \\
\hline Respiratory* & 1.68 & 1.07 to 2.64 & 0.024 \\
\hline Cardiac $^{*}$ & 0.32 & 0.15 to 0.64 & 0.0023 \\
\hline Congestive heart failure* & 1.44 & 0.78 to 2.71 & 0.25 \\
\hline Angina/myocardial infarction* & 1.17 & 0.46 to 3.12 & 0.57 \\
\hline Tumour* & 3.75 & 1.74 to 8.66 & 0.001 \\
\hline Stroke* & 1.41 & 0.76 to 2.64 & 0.28 \\
\hline Infections* & 0.56 & 0.27 to 1.12 & 0.11 \\
\hline
\end{tabular}

${ }^{*}$ Compared with not having the particular disease

the $\mathrm{UK}^{1-6}$; there are, however, few data of this kind from the UK. Indeed, the correlation between patterns of medical investigation and LOS is not well reported in the published literature.

Black and Pearson recently reported a change in the trend for average LOS: an increase from 6.8 days to 6.95 days between 1999-2000 and 2000-2001 was observed. ${ }^{15}$ This amounts to a $2.5 \%$ increase overall, but the figure for general internal medicine (including elderly care medicine) was $6.6 \%$. This is of concern since inpatient beds are a costly resource, which is ever more precious as demands on the NHS grow through an increasing number of annual hospital admissions. Therefore, measures that identify, with a view to influencing, factors that prolong hospitalisation are of value.

One of the main contributors to prolonged LOS in the UK is discharge delay pending social care placement or the initiation of community support services. ${ }^{15}$ Identified factors predicting prolonged LOS in other countries include specialty of attending physician, nosocomial infection, and delay in obtaining laboratory or radiological examination results. ${ }^{8-12}$ Among the elderly, diagnoses of fall, dementia, fracture, neoplasm, bronchitis, arterial disease, and hyponatraemia are known to be associated with longer LOS. ${ }^{13} 14$

The single most useful patient characteristic for predicting LOS, in our data, was patient age; presumably this reflects a greater need for pre-discharge social care planning in elderly patients. One may assume that elderly patients would have a greater number of more complex medical problems contributing to prolonged LOS; however, Fillit et al reported that frail elderly patients who needed only acute medical (but not social) care had similar LOSs to younger patients. ${ }^{11}$ Furthermore, they reported that, within the group requiring social care provision, early and frequent input from the social work department shortened LOS. Organisational strategy, therefore, is emerging as a major potential tool for tackling the NHS resource crisis. Such thinking is supported by our findings that patients admitted on a Friday had a longer LOS. Patients on medical wards had a significantly longer LOS; however, these data are biased by a large number of short stay patients included in the emergency observation ward. However, organisational factors alone do not fully account for LOS, medical variables also contribute. This has been demonstrated in the treatment of community acquired pneumonia, whereby timely administration of an appropriate antibiotic is seen to shorten LOS. ${ }^{16}$

While the specialty of the attending physician has, by other investigators, been shown to influence $\mathrm{LOS}_{,}{ }^{8}$ no significant difference in median LOS was observed between the 14 different consultants in our study. Perhaps these data are influenced by the impact of non-consultant grade doctors on LOS. It seems likely that such determinants of care and LOS may be equalised to some extent by the rotation of trainees between consultants.

Some interesting findings emerged in the relationship between LOS and the ordering of certain medical investigations. Those patients who had a chest radiograph ordered on the PTWR stayed significantly longer. Whether this is a marker of cardiorespiratory disease or, more simply, of advanced age is unclear, but it was an unexpected predictor of a prolonged inpatient episode. Of interest, ECG, another commonly requested investigation on the PTWR, had no effect on LOS. Indeed, other investigations that one may expect to be correlated with extended LOS, such as computed tomography imaging of the chest, abdomen or pelvis, or with shortened LOS, such as venography, were not; it may be that either the "typical" in one's mind is over-represented or the cohort studied was skewed.

The data revealed differences in the ordering of medical tests during the PTWR between consultant physicians. Significant differences in requesting of barium enema, computed tomography of the brain, chest, abdomen, or pelvis and abdominal ultrasonography were observed. This is to be expected since, while defined standards for the management of several diseases exist, there is often a lack of consensus or guidelines regarding the investigation of a patient with a given constellation of symptoms and signs. In those instances in which guidelines do exist, a decision to investigate beyond these may be taken in response to additional findings, fear of litigation, ease of investigation availability, personal or anecdotal experience, patient psychosocial factors, or the wish to have one's clinical judgment supported by an objective test. ${ }^{17}$

There is particularly high variability in respect of gastroenterological investigations. This could reflect differential ease of access; however, it seems likely that this might be a group of investigations (especially endoscopy) that is subject to a higher, perhaps inappropriate, rate of requesting by nongastroenterologists.

Winkens and Dinant reason that investigations are overused based on data from the Netherlands, which reveal an increase in nationwide expenditure on medical tests of $7 \%$ per annum without an associated increase in health status. ${ }^{1}$ Furthermore, they comment on the ineffectiveness of guideline distribution without accompanying active interventions to influence behavioural change. Costantini et al have, however, reported an overall positive attitude towards guidelines for investigation ordering among doctors; notably this was greatest among senior staff. ${ }^{17}$

While opinion may be divided concerning the implementation of changes in the ordering of medical tests by audit, peer review, education or computerised prompting systems, the potential benefits are great. Therefore, the opportunity to move along the path of rationalising, and perhaps unifying, investigation practice should be pursued.

\section{ACKNOWLEDGEMENTS}

We thank Ms Denise Lynd, Information Department, Belfast City Hospital, for assistance with retrieval of LOS data, and Dr D R T Shepherd, Clinical Director of Acute Medicine at Belfast City Hospital, for critical appraisal of the manuscript.

\section{Authors' affiliations}

R McMullan, Departments of Infectious Disease and General Medicine, Royal Victoria Hospital, and General Internal Medicine, Belfast City

Hospital, Belfast, UK 
B Silke, General Internal Medicine, Belfast City Hospital, Belfast, UK, Therapeutics and Pharmacology, Trinity College Dublin, Trinity Centre, and Division of Internal Medicine, St James' Hospital, Dublin, Ireland K Bennett, Department of Pharmacology and Therapeutics, Trinity College Dublin, Trinity Centre, and Division of Internal Medicine, St James' Hospital, Dublin, Ireland

S Callachand, General Internal Medicine, Belfast City Hospital, Belfast, UK

\section{REFERENCES}

1 Winkens R, Dinant GJ. Rational cost effective use of investigations in clinical practice. BMJ 2002;324:783-5.

2 Marik PE, Rakusin A, Sandhu SS. The impact of the accessibility of cranial CT scans on patient evaluation and management decisions. J Intern Med 1997;241:237-43.

3 Epstein AM, McNeil BJ. Physician characteristics and organisational factors influencing use of ambulatory tests. Med Decis Making 1985;5:401-15.

4 Kravitz RL, Callahan EJ. Patients' perceptions of omitted examinations and tests. J Gen Intern Med 2000;15:38-45.

5 Durham JA, McLeod DK. Use of diagnostic imaging services in the central region by general practitioners. N Z Med J 1999;112:233-6.

6 Cohen O, Kahan E, Zalewski S, et al. Medical investigations requested by patients: how do primary care physicians react? Fam Med 1999;31:426-31.
7 Little $\mathbf{P}$, Cantrell T, Roberts L, et al. Why do GPs perform investigations? Fam Pract 1998; 15:264-5.

8 Aguirre-Gas H, Garcia-Melgar M, Garibaldi-Zapatero J. The factors associated with a lengthy hospital stay in a third level unit. Gaceta Medica de Mexico 1997:133:71-7.

9 Fellin G, Apolone G, Tampiere A, et al. Appropriateness of hospital use: an overview of Italian studies. Int J Qual Health Care 1995;7:219-25.

10 Schluep M, Bogousslavsky J, Regli F, et al. Justification of hospital days and epidemiology of discharge delays in a department of neurology. Neuroepidemiology 1994;13:40-9.

11 Fillit H, Howe JL, Fulop G, et al. Studies of hospital stays in the frail elderly and their relationship to the intensity of social work intervention. Soc Work Health Care 1992;18:1-22.

12 Saravay SM, Steinberg MD, Weinschel B et al. Psychological comorbidity and length of stay in the general hospital. Am J Psychiatry 1991;148:324-9.

13 Onen F, Abidi H, Savoye L, et al. Emergency hospitalisation in the elderly in a French University Hospital. Aging 2001;13:421-9.

14 Zanocchi M, Maero B, Maina P, et al. Factors predicting a prolonged hospital stay in elderly patients. Minerva Med 2002;93:13-43.

15 Black D, Pearson M. Average length of stay, delayed discharge and hospital congestion. BMJ 2002;325:610-11.

16 Battleman DS, Callahan M, Thaler HT. Rapid antibiotic delivery and appropriate antibiotic selection reduce length of hospital stay of patients with community-acquired pneumonia. Arch Intern Med 2002;162:682-8.

17 Costantini O, Papp KK, Como J, et al. Attitudes of faculty, housestaff and medical students towards clinical practice guidelines. Acad Med 1999;74:1138-43.

\section{FILLER}

\section{Severe herpes zoster after infliximab infusion}

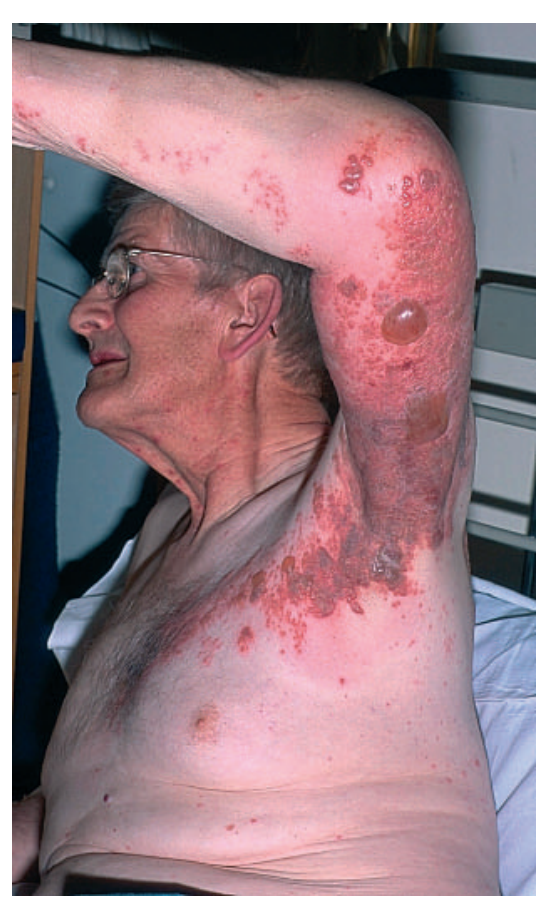

his 72 year old man developed an ache in his shoulder after his second infusion of infliximab $(3 \mathrm{mg} / \mathrm{kg}$ ) for his rheumatoid arthritis. By the next day vesicles had developed in the $\mathrm{T} 3$ dermatome. He visited his general practitioner who prescribed aciclovir but unfortunately he did not take it as he worried about aciclovir interacting with his other medications. Two days later he visited the rheumatology department with a severe herpes zoster rash (fig 1). With increased prescribing of biological therapy, severe forms of herpes zoster rashes are going to become much more common.

A Kinder, S Stephens, N Mortimer, P Sheldon Leicester Royal Infirmary, Infirmary Square, Leicester LE1 5WW, UK; alisonkinder@dsl.pipex.com

Figure 1 Severe herpes zoster in the T3 dermatome (published with patient's permission). 